\title{
Editorial for the special issue: vulnerability to natural hazards - the challenge of integration
}

\author{
Sven Fuchs $\cdot$ Christian Kuhlicke • Volker Meyer
}

Received: 9 April 2011/Accepted: 19 April 2011/Published online: 17 May 2011

(c) Springer Science+Business Media B.V. 2011

Extreme geophysical events, such as those which recently occurred in the United States (hurricane Katrina), Europe and Pakistan (floods), New Zealand and Japan (earthquake and tsunami), have focused the attention of the global community to the topic of vulnerability to natural hazards. Why has there been so little progress in our ability to mitigate and adapt to natural hazards? White et al. (2001) summarised this paradox in an article with the title 'Knowing better and losing even more - the use of knowledge in hazard management'. While there are many reasons for this paradox, one might also state that truly interdisciplinary research appears to be necessary to tackle this problem as it allows for the analysis of the dynamics and multi-faceted characteristics of vulnerability.

Over recent years, the term vulnerability has become a buzz word in natural hazard and climate change research. At the same time-and this is may be one reason for the increasing popularity — vulnerability is a quite fuzzy term: Dozens of different definitions of vulnerability have emerged and are used in different disciplinary context, e.g., in pure and applied hazard research (Fuchs 2009), in the development context (e.g. Chambers

S. Fuchs $(\bowtie)$

Institute of Mountain Risk Engineering, University of Natural Resources and Life Sciences,

Peter-Jordan-Str. 82, 1190 Wien, Austria

e-mail: sven.fuchs@boku.ac.at

S. Fuchs

Faculty of Geography, Lomonosov Moscow State University, Leninskie gory 1, 119991 Moscow, Russian Federation

C. Kuhlicke

Department of Urban and Environmental Sociology, Helmholtz Centre for Environmental Research - UFZ, Permoserstraße 15, 04318 Leipzig, Germany

e-mail: christian.kuhlicke@ufz.de

C. Kuhlicke

Department of Geography, King's College London, Strand, London WC2R 2LS, UK

V. Meyer

Department of Economics, Helmholtz Centre for Environmental Research - UFZ,

Permoserstraße 15, 04318 Leipzig, Germany

e-mail: volker.meyer@ufz.de 
1989; Watts and Bohle 1993), related to the question of sustainability (Turner II et al. 2003) and climate change (Füssel and Klein 2006), to name only a few. The only common understanding among these definitions seems to be that vulnerability is a concept that allows to somehow considering the impacts or receptors of natural hazards and not only the hazard itself.

One reason for the multiplicity of different definitions and concepts is surely that different scientific disciplines are working with this term: natural scientists, engineers, social scientists or economists, to name just a few. Each discipline defines vulnerability in a way which fits to their disciplinary purposes. The variety and diversity of definition is also becoming apparent when reading through the individual chapters of this multidisciplinary special issue. This special issue on vulnerability is the result of a corresponding session entitled 'Competing approaches to vulnerability in human and physical geography', which was held at the biannual German Geographers Conference in Vienna, Austria, in September 2009. Out of this session, nine papers resulted which are included in this issue.

Geographers have a long-standing interest in natural hazards and vulnerability research, dating back to the initial work of Gilbert F. White who submitted his ground-breaking dissertational thesis on flood hazards and flood plain management to the University of Chicago in 1942 (White 1945). Since then, geographers have developed different interpretations about the occurrence and underlying root causes for natural hazards and disasters (e.g. Hewitt and Burton 1971; Watts and Bohle 1993; Cutter 1993; Blaikie et al. 1994; Liverman 1994).

The overarching thematic umbrella for the individual contributions of this special issue centres on the question to what extent the integration between natural and social scientific approaches to vulnerability is possible. In this vein, the issue contains different perspectives on vulnerability and provides a forum to scrutinise to what extent these perspectives can be combined and processed in an integrative manner (and not simply as dualistic entities). The motivation for organising the session and for preparing this special issue is thus to document different and possibly opposing attempts to capture vulnerability to natural hazards. We therefore asked contributing authors explicitly (1) about their understanding of vulnerability and (2) in which way their approach is integrative.

\section{Integration in vulnerability research: an outline}

Based on the contributions included in this special issue, the challenge of integration refers to three different aspects:

Integration of the components of vulnerability This refers to the different components most vulnerability studies consider such as exposure, susceptibility/sensitivity as well as coping and adaptive capacities or resilience and how to integrate the various components into an overall understanding, framework or model. Initially in vulnerability, research the focus was on the internal side (coping capacity of people or systems) as well as on the external side of vulnerability (exposure of people to stress or pertubation ${ }^{1}$ and to societal

\footnotetext{
1 Stress is a continuous or slowly increasing pressure, commonly within the range of normal variability. Stress often originates and stressors (the sources of stress) often reside within the system. A perturbation is understood here as a major threat beyond the normal range of variability in which a system operates, and commonly originates beyond the system or location in question (Turner II et al. 2003). From a social scientific perspective, such perturbations are becoming problematic as expectations of a social system can no longer be fulfilled due to a radically and rapidly changing environment (Kuhlicke 2010; Lorenz in press).
} 
structures they could not change; Chambers 1989). Later on, it was increasingly regarded as more important to focus on people's capacities to cope with and adapt to hazardous events and processes (Anderson and Woodrow 1989; Kuhlicke 2010). Natural science approaches on the other hand mostly focus on the susceptibility of physical elements at risk to natural processes (e.g. Fuchs et al. 2007) in order to provide information necessary for operational risk analyses and technical mitigation. Through the rise of research on the consequences of climate change, another categorisation gained relevance which includes the components of exposure, sensitivity and adaptive capacity and/or resilience (Turner II et al. 2003, for a more thorough discussion see Hufschmidt, in this volume).

Integration of methods for assessing vulnerability This refers to the different methods which are used in vulnerability assessments and to what extent they are integrated for exploring vulnerability from different angles or for developing a holistic picture. The methodological repertoire is quite considerable in vulnerability science reaching from locally embedded research modes to highly advanced integrative, mostly GIS-based modelling approaches. A general difference can be made between rather participatory, inductive vulnerability assessments aiming at a better understanding of actors' perceptions of their own vulnerabilities and capacities in order to develop locally embedded adaptation and coping strategies on the one hand. And on the other hand, rather taxonomic, deductive vulnerability assessments aim at identifying, comparing and quantifying vulnerability of areas, groups or sectors by relying on different indicators and indices (cf. Wisner 2006).

Target dimension of vulnerability assessment This refers to the different dimensions of vulnerability such as, for instance, whether an appraisal is focusing on economic consequences, the consequences for the built environment or on environmental or social vulnerabilities. Many vulnerability assessments based on economics or engineering sciences are concerned with the evaluation of monetary damages on assets, especially on buildings and their inventories (Meyer and Messner 2005). In contrast, social scientists are more concerned with the impacts on and coping and adaptation capacities of people, households and communities and the underlying root causes (e.g. Blaikie et al. 1994). The challenge of integration hence relates to the question whether it is possible (or desirable) to consider all dimensions, i.e., economic, social and ecological impacts on an integrated understanding and assessment of vulnerability.

We asked the individual contributors explicitly to define their view of vulnerability and how it possibly differs from other approaches. Table 1 gives an overview about the different emphasises of the individual contributions with regard to the different aspects outlined above.

\section{Overview about the individual contributions}

Gabi Hufschmidt conducts a comparative analysis of six vulnerability models aiming to identify differences and similarities between several approaches of vulnerability. Her analysis yields a set of characteristics for explaining the condition of vulnerability (multiple contexts, multiple dimensions, temporal variability, multiple scales and scale-interdependency). The author defines vulnerability as the degree of damage that can be expected depending on the characteristics of an 'element at risk' with respect to a certain hazard. Her contribution argues that 'adaptation' and 'adaptive capacity' are key elements of vulnerability, and it is demonstrated that 'adaptation' and 'adaptive capacity' serve as hinges not only for conceptualising vulnerability but between 'vulnerability' and 


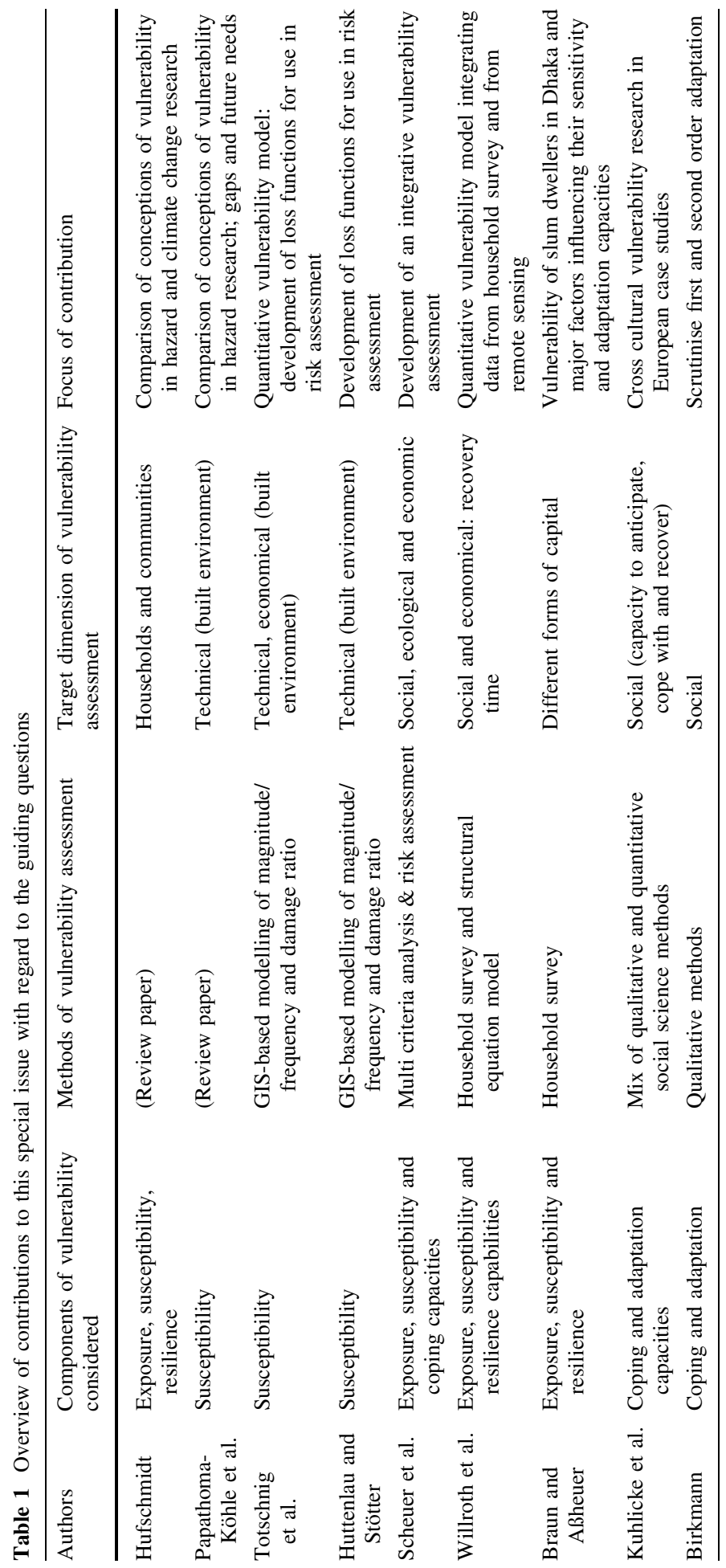


'resilience' alike. She concludes with a summarising model of vulnerability focussing on the household and community scale displaying the key findings of this contribution.

Maria Papathoma-Köhle, Melanie Kappes, Margreth Keiler and Thomas Glade address the state of the art and future needs for vulnerability assessment focusing on vulnerability of the built environment with a focus on the susceptibility of building. The authors are reviewing existing methods for vulnerability assessment related to mountain hazards. Vulnerability is defined here as a pre-existing condition that relates to those characteristics and properties of the elements at risk that increase their susceptibility to the impact of hazards. The study uncovers that most of the reviewed methods consider vulnerability to be the degree of loss of a specific element at risk to a hazard of a given magnitude. By analysing the existing approaches, difficulties in their implementation (data availability, time consumption) and differences between them regarding their scale, the consideration of the hazardous phenomenon and its properties, the consideration of important vulnerability indicators and the use of technology such as GIS and remote sensing, are identified. Based on these observations, future needs in the field of vulnerability assessment are indicated. Even if these needs are rooted in natural sciences, the authors argue for the necessity of such studies due to the fact that vulnerability is hazard dependant and therefore such information is the prerequisite for an integrative assessment of vulnerability.

Reinhold Totschnig, Walter Sedlacek and Sven Fuchs follow a similar approach and focus on the susceptibility of residential buildings to torrent hazards in alpine regions. Vulnerability is defined as the expected degree of loss for an element at risk due to the impact of a defined hazardous event within a defined period of time and a defined location. Vulnerability values describe the susceptibility of elements at risk to damage. By taking a local perspective, they develop a quantitative vulnerability function applicable to residential buildings exposed to fluvial sediment transport. The method applied followed a spatially explicit empirical approach within a GIS environment and was based on process intensities, the spatial characteristics of elements at risk, average reconstruction values and loss data. It is shown that the vulnerability of a specific location and within a considered point of time is triggered by the hazardous event and the related physical susceptibility of structures, such as buildings located on a torrent fan (physical vulnerability). Depending on the specific institutional settings, economic vulnerability of individuals or of the society results, which provides a possible link to vulnerability approaches in social sciences. The authors discuss how the concept of vulnerability, as being used in natural sciences, can be extended. This could possibly be done by integrating possible reasons why a physical susceptibility of structures exists and by also considering compensation mechanisms and coping strategies of households.

Matthias Huttenlau and Johann Stötter also focus on the vulnerability of the built environment. Here, vulnerability is considered as structural susceptibility of the risk indicators of buildings and inventory in the framework of natural hazard risk analyses by taking a regional perspective of storm loss modelling. Their contribution is focused on both (i) different concepts of the natural hazard risk and specific expressions in the context of vulnerability and (ii) the exemplary application of the natural scientific-technical vulnerability concepts to analyse potential losses in the State of Tyrol (Austria). With respect to the chosen regional approach, the authors claim a lack in data concerning vulnerability assessment, in particular related to an inventory on elements at risk exposed.

Sebastian Scheuer, Dagmar Haase and Volker Meyer consider in their article the vulnerability against flooding in the city of Leipzig, Germany. For their approach of flood risk mapping, a quite broad definition of vulnerability is applied. It includes as components the elements at risk with their values and susceptibilities but also the hazard and its probability 
and therefore comes close to the concept of risk and the concept of vulnerability applied in the climate change community (see e.g. McCarthy et al. 2001). Following Kelly and Adger (2000), they furthermore differentiate between a starting point view of vulnerability that excludes and an end point view of vulnerability that includes the risk reducing effects of coping capacities. Both risk and coping capacity are considered in the multicriteria risk mapping approach with an economic, social and ecological dimension. Integration is understood here as a) an integration of the social, economic and ecological consequences and b) as an integration of the different components of flood risk assessment from the exposure of elements at risk to hazards of different probabilities to their susceptibility and coping capacity.

Philipp Willroth, Javier Revilla Diez and Narumon Arunotai are dealing in their paper with the vulnerability against tsunamis in the area of Khao Lak, Thailand, an area seriously hit by the 2004 tsunami. They consider vulnerability as being composed by exposure, sensitivity, and coping capacity and/or resilience capabilities. Based on this understanding of vulnerability, a quantitative, structural equation model is developed which includes indicators for these three components and uses recovery time as the main outcome measure of vulnerability. The integrative potential of the concept of vulnerability is seen in this contribution in the integration of different empirical methods or data sources, e.g., the integration of household survey data and remote sensing data for different indicators of vulnerability in one statistical model.

Boris Braun and Tibor Aßheuer focus on megacities of the global south, namely the capital of Bangladesh, Dhaka. The authors also consider different components of vulnerability and include people's exposure, sensitivity and resilience to the impact to flood events. More particular, the paper analyses the vulnerability of slum dwellers in Dhaka and highlights the major factors behind their sensitivity to floods and their ability to adapt to the related changes. The empirical findings presented are based on a questionnaire survey covering 625 households in five slum areas of Dhaka. The authors therefore consider different forms of capital (physical, financial, human, social and natural) to better understand people's livelihoods assets. The data suggest that social capital plays an important role with regard to the ability of slum dwellers to find ways to live with the floods. Regardless of how strongly people are affected, mutual help and support are dominant features in times of crises. Their paper suggests that while poorly educated and resourced slum dwellers are highly vulnerable to external shocks, they still show a surprising capacity to cope with natural calamities.

Christian Kuhlicke, Anna Scolobig, Sue Tapsell, Annett Steinführer and Bruna De Marchi present findings from social vulnerability assessments conducted in different case studies of flood events in Europe (Germany, Italy and the UK). The authors focus on the coping and adaptation capacities of households with regard to their capacity to anticipate, cope with and recover from the impacts of recent flood events. Therefore, the case studies relied upon a common set of comparable indicators but also adopted a context sensitive, qualitative approach. A shared finding across the case studies was that it was not possible to identify a common set of socio-economic-demographic indicators to explain social vulnerability of groups and/or individuals for all phases of the disastrous events. The results underline that vulnerability is a product of specific spatial, socio-economicdemographic, cultural and institutional contexts imposing not only specific challenges to cross-country research concerning social vulnerability to flooding but also to attempts at assessing social vulnerability in general.

Jörn Birkmann's contribution deals with coping and adaptation processes to natural hazards and (potential) climate change impacts. Selected response measures to natural 
hazards are critically reviewed with respect to the actual and potential consequences these measures might imply for additional adaptation needs and changes within social-ecological systems. In this context, Birkmann introduces the concept of first- and second-order adaptation processes in order to underline the cascade process that adaptation implies, the potentials for failure and the limits of adaptation. In its final part, the paper discusses the findings in the light of selected theoretical approaches that might help to understand how stabilisation and destabilisation processes are influenced or even triggered by adaptation measures.

\section{Challenges of integration}

Based on the individual contributions to this special issue, some general challenges for assessing vulnerability in an interdisciplinary context are outlined with respect to components of vulnerability, as well as methods and the target dimension of vulnerability assessment.

\subsection{Components of vulnerability}

Table 1 reveals that four articles consider different components of vulnerability, three focus on the susceptibility of the built environment (mostly residential buildings) and two on coping and adaptation capacities of people. A closer look at the papers shows that most definitions share common ground but also reveal distinct differences between on how single components are defined and demarcated from each other. This applies particularly to the separation between hazard, exposure and susceptibility/sensitivity and on how the individual components are operationalised in the respective research projects.

As outlined by David Alexander ('a hazard is not hazardous unless it threatens something; [and] vulnerability does not exist unless some elements at risk are threatened by something', Alexander 2004, p. 267, original emphasis), exposure can be seen as the relationship of elements at risk to the hazard and is therefore somehow a bridging element between the natural and social scientific part of risk. However, as outlined by Hufschmidt in her contribution to this issue, the term is differently understood and operationalised in vulnerability analyses. Some contributions such as Papathoma-Köhle et al. or Totschnig et al. consider exposure as being external as part of their analysis, but do not define it as part of vulnerability itself. Vulnerability, in this understanding, is mostly dedicated to the susceptibility component. On the other hand, contributions such as Braun and Aßheuer, Willroth et al. and Scheuer et al. explicitly include exposure in their definition of vulnerability and therefore refrain from a strict differentiation of hazard and vulnerability. Both groups of contributions, however, end up with quite similar assessments. Although their definition of vulnerability is different, the scope of the studies is relatively similar: Elements at risk are set in relation to a hazard, and their susceptibility against such hazards is analysed in order to assess the potential impacts on the system.

One could argue that a strict definition and use of the term vulnerability could solve these differences. However, the discussion during the last decades and also the contributions to this special issue underline that the desire for a one common definition of vulnerability is rather illusionary, as a definition of a research object depends largely on the purpose or on the interest of the analysis, and this interest differs between disciplines and their representatives. 
Therefore, from our point of view, it is important to clearly describe and define which components of risk and/or vulnerability assessment are considered in each individual study. These components may include (1) the frequency and magnitude of a hazard, (2) elements at risk and their exposure to this hazard, (3) the susceptibility of these elements at risk to the hazard and (4) the coping and adaptation capacities of various categories of elements at risk. As seen above, these different components could be seen either internal or external to vulnerability, but if they are clearly named and described, this might contribute to a reduction of confusion and possibly contribute to a mutual understanding between disciplines/schools of thoughts.

\subsection{Methods of vulnerability assessment}

The term vulnerability is conceptualised in hazard and disaster management in various ways. As a consequence, the notion of vulnerability is as divergent as the methods and theories of disciplines involved in vulnerability research. Social scientists and natural scientists often address different issues when they are using the term vulnerability. Consequently, participatory, bottom-up oriented vulnerability assessments and deductive topdown approaches to vulnerability have been considered for quite a long time as rather opposing each other. While participatory approaches aim at empowering people by trying to stimulate the development of locally owned and embedded adaptation and coping strategies, deductive approaches are targeted to quantify the vulnerability of elements and people at risk in order to develop a detached and comparable vulnerability measure.

Thereby, it is often argued that taking the perspective of natural sciences and consequently neglecting any social implications arising from hazards, vulnerability is considered as a functional relationship between a process magnitude, the resulting physical impact on elements at risk, and exposed values. As a result, loss functions such as typically used in insurance business or in economics is deduced. In contrast, if the concept of vulnerability is defined anthropocentrically by taking a perspective from social sciences, people's exposition to and capacity to cope with or adapt to a hazard is of concern. In this view, vulnerability is mostly considered as a result of social processes and structure (and not of natural processes). It is hence concerned with how vulnerable conditions are socially produced and constructed. Apparently, such an understanding not only uses different methods but is also based on very different ontological and epistemological assumptions.

\subsection{Target dimension of vulnerability assessment}

The objective of an integrative vulnerability assessment is to include all relevant impacts on a system. Following the concept of sustainability, this would mean that all dimensions of vulnerability, i.e., economic, social as well as ecological impacts of a certain hazard should be considered. However, this should not lead to a division of work between disciplines in a sense that economists only focus on damages to the economy, social scientists centre on effects on people and ecologists deal with environmental consequences. In contrast, the challenge from an interdisciplinary research would be to bring together the methodological expertise of different disciplines in order to come to an integrated assessment of vulnerability or risk. Apparently, such an exercise is demanding both resource wise and intellectually as no discipline could claim a position of superiority. A central task could hence be to start thinking about a common definition of the problem to exchange views about definitions, concept and underlying worldviews and values. Above 
all, such an endeavour would need to be based on mutual respect among disciplines and intellectual curiosity.

\subsection{Integrating natural and social sciences approaches to vulnerability}

What this special issue also testimonies is the challenge of integration between natural and/ or social scientific approaches in the field of vulnerability research. Only a few contributions strictly attempt to overcome the divide between both approaches, whereas all contributors attempt to develop some kind of integrative perspective (e.g. methodologically) on vulnerability. This might appear as particularly surprising against the background that most authors are affiliated with academic departments and institutions that often exhibit interdisciplinary and even multi-disciplinary research environments.

It has often been argued (also by geographers) that the discipline of geography is particularly appropriate for such a combined and therefore interdisciplinary field of research due to an exceptional capacity of problem-solving. This capacity is justified with the focus on the interrelation of the social and physical environment and studies on the spatial and temporal distribution of phenomena, processes and features. The possibility that physical and human geographers could share methods and techniques has been debated for a long time, and many connections have been proposed (Viles 2005). Because physical geographers are scientists who largely study natural phenomena, and human geographers generally study human communities, geography as a whole spreads over the divide between the sciences and the arts, in terms of both subject matter and approaches to study (Viles 2005).

However, if geography shall perform a bridge function, then both dimensions, the natural scientific and the social scientific, have to be at least expanded to other fields of geographic research, which is rooted in the systematic analysis of interrelations between multiple spheres of geographic discipline (Hartshorne 1959). Other sources, however, argue that it is the lack in distinct theories and constructs of ideas resulting from the relatively shallowness in geographical conceptualisations that weakens the discipline in competition to related disciplines such as sociology, economy, psychology, geology and physics (Clifford 2002; Turner II 2002; Johnston 2005).

Yet, it is not an integration of methods and concepts that provide the disciplinary enclosure in natural hazard risk research; instead, it is the interaction between methods applied in the sciences and the arts. As argued by Weichhart (2005) by the metaphor of human-environment interaction, research on natural hazards and risk cannot be simply undertaken by reintegrating natural sciences and social sciences, and as such physical and human geography, it is rather the construction of a 'third pillar' between the two poles of science as an independent object of knowledge gain which is characterised by a complex of specific research questions. These specific research questions will not be comprehensively answered by applying individual methods rooted either in physical geography or in human geography, or in natural sciences and social sciences.

Moreover, and this is also shown by the contributions to this special issue, such a strict division between approaches based on physical or human geography often does not exist: By applying methods rooted in economics or economic geography, contributions from Scheuer et al. and Willroth et al. are based on a similar understanding of risk and vulnerability as natural scientific approaches. Natural scientific contributions such as Totschnig et al. make use of economic methods in order to provide a bridge function to social sciences. This connectivity between natural scientific and approaches from economics can be explained by the quite similar understanding of the concept of risk (see e.g. Banse and 
Bechmann 1998). Both disciplines understand risk as a function of probability and consequences which can be measured and quantified.

However, a task to be further elaborated is to explore how some key concepts could provide the basis for both poles of geography (Massey 2001), such as the concept of space (Golledge 2002; Unwin and Rose 2004) as a fundamental in both human geography (Thrift 2003) and physical geography (Kent 2003). Another such concept is time, which involves the paradigms of dynamical systems, nonlinearities, chaotic behaviour and panarchy in physical geography (Gregory 2000; Thornes 2003), and the issue of (social) change with respect to human geography (Taylor 2003). General points of commonality are issues of scale and hierarchies, and the increasing use of dynamic rather than equilibrium ideas and metaphors in both physical and human geography (Viles 2005).

Nevertheless, this special issue documents that representatives of different disciplines, and as such scholars trained in or working in the field of physical geography, social geography, and economic geography, have started communicating with each other and to present their views, definitions, insights and results in common sessions and conferences. This is surely the first step for any kind of the interdisciplinary research endeavour targeted. Whether and to what extent geography is able to act as a mediator or negotiator between the two main groups of science and whether geography is able to link the spheres of nature and society in an integrative way (Weichhart 2008) is a matter of future forms of collaboration. This statement was also a major conclusion from the underlying session held at the German Geographers Conference in Vienna.

Finally, we would like to express our sincere thanks to the management and editorial board of the Natural Hazards journal, above all Petra van Steenbergen, Senior Publishing Editor at Springer, Thomas Glade as the Coordinating Editor, as well as Preetha Arulmohan and Ayrene Dialogo from the Editorial Office of Springer. Moreover, we would like to acknowledge the sincere efforts of all the reviewers who supported this special issue with their knowledge on different aspects of vulnerability and their constructive criticism that helped us to further develop the individual argumentations in the papers. We would also like to thank all the colleagues who contributed to this special issue, above all for their patience during the process of manuscript production and revision.

\section{References}

Alexander D (2004) Natural hazards on an unquiet earth. In: Matthews J, Herbert D (eds) Unifying geography, shared future. Common heritage, Routledge, London, pp 266-282

Anderson M, Woodrow P (1989) Rising from the ashes: development strategies in times of disasters. Intermediate Technology Publications, London

Banse G, Bechmann G (1998) Interdisziplinäre Risikoforschung-eine Bibliographie. Westdeutscher Verlag, Opladen

Blaikie P, Cannon T, Davis I, Wisner B (1994) At risk. Natural hazards, people's vulnerability and disasters. Routledge, London

Chambers R (1989) Vulnerability, coping and policy. IDS Bulletin 20:1-7

Clifford N (2002) The future of geography: when the whole is less than the sum of its parts. Geoforum 33:431-436

Cutter S (1993) Living with risk. Edward Arnold, London

Fuchs S (2009) Susceptibility versus resilience to mountain hazards in Austria-paradigms of vulnerability revisited. Natural Hazards and Earth System Sciences 9:337-352

Fuchs S, Heiss K, Hübl J (2007) Towards an empirical vulnerability function for use in debris flow risk assessment. Natural Hazards and Earth System Sciences 7:495-506

Füssel HM, Klein R (2006) Climate change vulnerability assessments: an evolution of conceptual thinking. Climatic Change 75:301-329 
Golledge R (2002) The nature of geographic knowledge. Ann Assoc Am Geogr 92:1-14

Gregory K (2000) The changing nature of physical geography. Arnold, London

Hartshorne R (1959) Perspective on the nature of geography. John Murray, London

Hewitt K, Burton I (1971) The hazardousness of a place: a regional ecology of damaging events. University of Toronto Press, Toronto

Johnston R (2005) Geography_coming apart the seams? In: Castrée N, Rogers A, Sherman D (eds) Questioning geography. Blackwell, Oxford, pp 9-25

Kelly PM, Adger WN (2000) Theory and practice in assessing vulnerability to climate change and facilitating adaptation. Clim Change 47:325-352

Kent M (2003) Space: making room for space in physical geography. In: Holloway S, Rice S, Valentine G (eds) Key concepts in geography. Sage Publications, London, pp 109-130

Kuhlicke C (2010) The dynamics of vulnerability: some preliminary thoughts about the occurrence of 'radical surprises' and a case study on the 2002 flood (Germany). Nat Hazards 55:671-688

Liverman D (1994) Modeling social systems and their interaction with the environment: a view from geography. In: Groffman P, Likens G (eds) Integrated regional models. Chapman \& Hall, New York, pp $67-78$

Lorenz DF (in press) The diversity of resilience: contributions from a social science perspective. Nat Haz. doi:10.1007/s11069-010-9654-y

Massey D (2001) Talking of space-time. Transactions of the Institute of British Geographers 26:257-261

McCarthy JJ, Canziani OF, Leary NA, Dokken DJ, White KS (2001) Climate change 2001: impacts, adaptation, and vulnerability. Cambridge University Press, Cambridge

Meyer V, Messner F (2005) National flood damage evaluation methods - a review of applied methods in England, the Netherlands, the Czech Republic and Germany. UFZ-Diskussionspapiere 21/2005

Taylor P (2003) Time: from hegemonic change to everyday life. In: Holloway S, Rice S, Valentine G (eds) Key concepts in geography. Sage Publications, London, pp 151-164

Thornes J (2003) Time: change and stability in environmental systems. In: Holloway S, Rice S, Valentine G (eds) Key concepts in geography. Sage Publications, London, pp 131-150

Thrift N (2003) Space: the fundamental stuff of human geography. In: Holloway S, Rice S, Valentine G (eds) Key concepts in geography. Sage Publications, London, pp 95-107

Turner B II (2002) Contested identities: human-environment geography and disciplinary implications in a restructuring academy. Proc Natl Acad Sci USA 92:52-74

Turner B II, Kasperson R, Matson P, McCarthy J, Corell R, Christensen L, Eckley N, Kasperson J, Luers A, Martello M, Polsky C, Pulsipher A, Schiller A (2003) A framework for vulnerability analysis in sustainability science. Proc Natl Acad Sci USA 100:8074-8079

Unwin T, Rose J (2004) Regions, area studies and the meaning of place. In: Matthews J, Herbert D (eds) Unifying geography. Common heritage, shared future. Routledge, London, pp 171-188

Viles H (2005) A divided discipline? In: Castrée N, Rogers A, Sherman D (eds) Questioning geography. Blackwell, Oxford, pp 26-38

Watts M, Bohle HG (1993) The space of vulnerability: the causal structure of hunger and famine. Progress in Human Geography 17:43-67

Weichhart P (2005) Auf der Suche nach der „dritten Säule”. Gibt es Wege von der Rhetorik zur Pragmatik? In: Müller-Mahn D, Wardenga U (eds) Möglichkeiten und Grenzen integrativer Forschungsansätze in Physischer Geographie und Humangeographie. Institut für Länderkunde, Leipzig, pp 109-136

Weichhart P (2008) Der Mythos vom „Brückenfach”. Geographische Revue 10:59-69

White G (1945) Human adjustment to floods: a geographical approach to the flood problem in the United States, Department of Geography. Research Paper, 29, Department of Geography, University of Chicago, Chicago

White G, Kates R, Burton I (2001) Knowing better and losing even more: the use of knowledge in hazards management. Environmental Hazards 3:81-92

Wisner B (2006) Self-assessment of coping capacity: participatory, proactive and qualitative engagement of communities in their own risk management. In: Birkmann J (ed) Measuring vulnerability to natural hazards: towards disaster resilient societies. United Nations University Press, New York, pp 316-329 